\title{
El futuro de Chile delineado en un mapa'
}

\author{
Rafael Sagredo Baeza²
}

\begin{abstract}
RESUMEN
Relacionando la cartografía con la ciencia y la política, se interpreta el primer mapa de Chile republicano delineado por Claudio Gay por encargo del Estado a mediados de la década de 1830, como la expresión de un proyecto institucional a través del cual los organizadores de la república proyectaron su obra hacia el futuro. En este contexto, el mapa se comprende no sólo como un medio para dar forma y representar el territorio, sobre todo, como un instrumento político que se anticipa a la realidad nacional que se fue configurando a lo largo del siglo XIX.
\end{abstract}

Palabras clave: Mapa de Chile, Claudio Gay, República, Ciencia.

\begin{abstract}
Relating cartography to science and politics, the first map of republican Chile, delineated by Claudio Gay and commissioned by the State in the mid-1830s, is interpreted as the expression of an institutional project through which the organizers of the republic projected their work towards the future. In this context, the map is understood not only as a mean to shape and represent the territory, but above all, as a political instrument that anticipates the national reality that was shaped during the nineteenth century.
\end{abstract}

Key words: Map of Chile, Claudio Gay, Republic, Science. 
Un mapa de Chile, en realidad el borrador de un mapa de Chile, para ser exactos, un boceto de mapa de apenas una porción del territorio considerado chileno a mediados de la década de 1830, es una de las expresiones más elocuentes del proyecto al que los organizadores de la república se sumaron en 1810 (Figura No 1). Será a partir de él, y de otros que lo siguieron, que mostraremos y explicaremos una de las formas en que fue concebido entonces el futuro del país. Una operación política, intelectual y científica que, al señalar un futuro deseado, inevitablemente refleja una imagen sobre el pasado, pero también del presente en el que se actúa. Uno que exige legitimar una política, pero también al grupo dominante en el poder, y que ve en la ciencia y el conocimiento un instrumento muy efectivo para mostrar la pertinencia histórica del orden existente y la viabilidad material de la opción independentista.

Figura No 1

Borrador del mapa de Chile de Claudio Gay

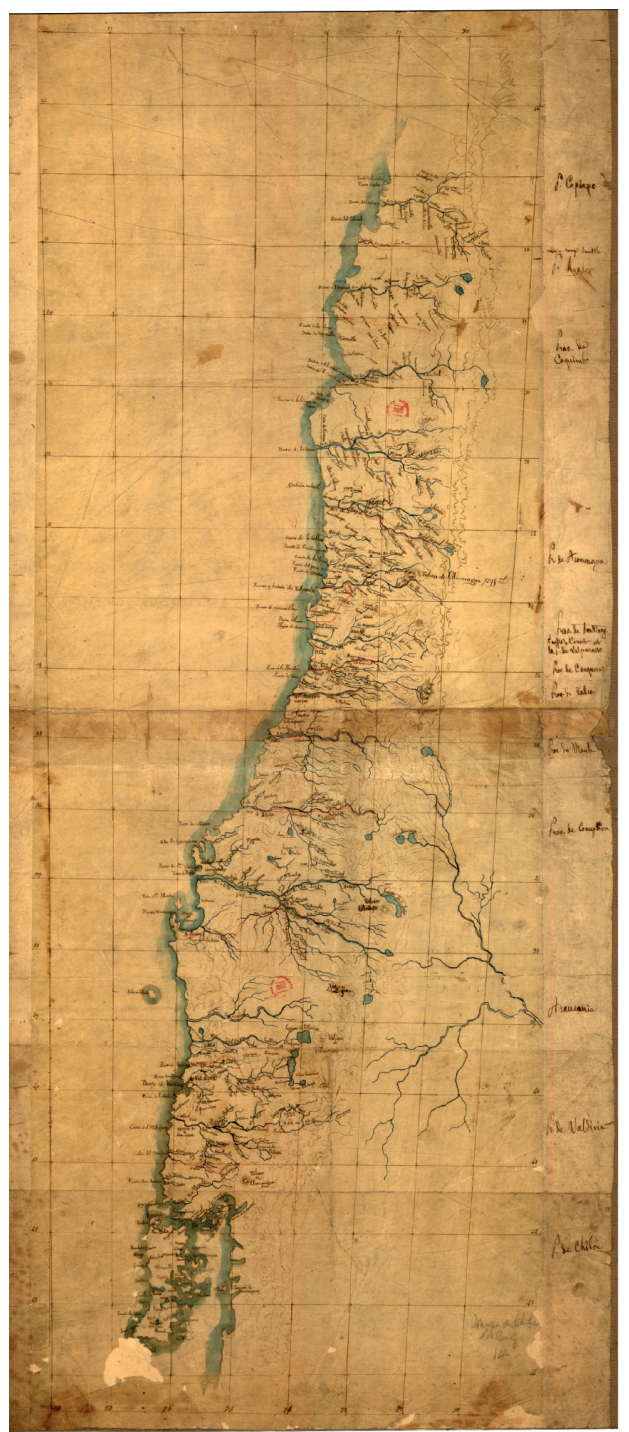

Fuente: Archivo Nacional Histórico. 
La representación, que llevada a una versión más pulcra, Claudio Gay llama "mi gran mapa" en una misiva dirigida al profesor de mineralogía Ignacio Domeyko en septiembre de 1841, había sido depositada por el naturalista "en el ministerio" antes de dejar Chile, siendo muy poco lo que se sabe de sus distintas versiones, debiendo contentarnos con deducir las alternativas de su elaboración y de su destino final a partir de las actividades desplegadas por el científico en el país antes de regresar a Francia en 1842, como de la información que ofrece en su correspondencia, en particular con Manuel Montt (Feliú Cruz y Stuardo Ortiz, 1962: 32 y 48). Dos fuentes esenciales también para identificar el proyecto, el futuro de Chile, que el Estado, las elites en el poder, concibieron posible gracias al trabajo científico. Es la concepción del mapa, de este primer mapa de Chile, como reflejo de la sociedad, de un espacio y de un tiempo concreto, como lo es la época de la formación de la república que, sin embargo, se proyecta en el tiempo a través de una representación intelectual-material de ella, cuya vigencia muestra su efectividad ${ }^{3}$. Una expresión de que "la historia no se desenvuelve sólo en el tiempo, también en el espacio" (Schlögel, 2007: 13). Que los sucesos tienen lugar en algún sitio, en escenarios que es preciso señalar, identificar y delinear, como Claudio Gay lo hace para Chile y su historia, con un mapa que, a diferencia de la mayoría de los que se publican, no está atrasado cuando aparece, sino que adelantado a la realidad que representa.

La carta que Gay había comenzado a elaborar desde su llegada al país en diciembre de 1828 corresponde a las primeras versiones o borradores, del que llegaría a ser el "Mapa para la inteligencia de la "Historia física y política de Chile", publicado en 1854 en su "Atlas" (Figura No 2). Ambos, en realidad, proyectos: uno, de un mapa de Chile, prometido desde que en 1830 fue contratado por el gobierno para emprender un viaje de exploración por el territorio nacional; el otro, el mapa publicado como parte de su "Historia física y política de Chile", de un Estado republicano y una nación entonces en proceso de organización y conformación respectivamente.

El mapa, y la obra de la que forma parte, permiten mostrar el espacio transformado en territorio nacional gracias al arte de representarlo cartográficamente, pero, sobre todo, cómo se concibió el mañana en la primera mitad del siglo XIX. Entonces fue que se imaginó un Estado capaz de ejercer soberanía sobre el territorio, población y recursos bajo su jurisdicción; pero también una sociedad, del cual era consecuencia, en el futuro, constituyendo una nación; objetivos que el conocimiento, el saber profesional, la ciencia y la tecnología ayudaron a materializar a lo largo del siglo XIX, entre otras razones, por la asociación con el progreso que corrientemente se atribuye a la ciencia.

Una dimensión poco conocida de nuestra trayectoria, pero esencial para comprender la forma en que se fue organizando la realidad natural e histórica nombrada Chile desde tiempos inmemoriales que, ahora como república, en la coyuntura de la independencia, asumió con entusiasmo y esperanzas su nueva condición y, con ella, la necesidad de dotar de un nuevo proyecto político a la comunidad que nacía a la vida independiente. Proyecto que se sirvió de la ciencia para materializarse y, sobre todo, hacerse viable. Que, en la instancia del ocaso de un mundo, el colonial, y el comienzo de otro, la república, y como ha sido asentado, se sirvió del mapa para señalar el tránsito de un orden, también espacial, a otro (Schlögel, 2007: 90-91).

Entonces reflejo de la irrupción de la política moderna y del individuo, y con ellos, la invención del futuro, es decir, de un proyecto por materializarse, el régimen republicano. 
Figura $\mathrm{N}^{\circ} 2$

"Mapa para la inteligencia de la "Historia física y política de Chile" de Claudio Gay

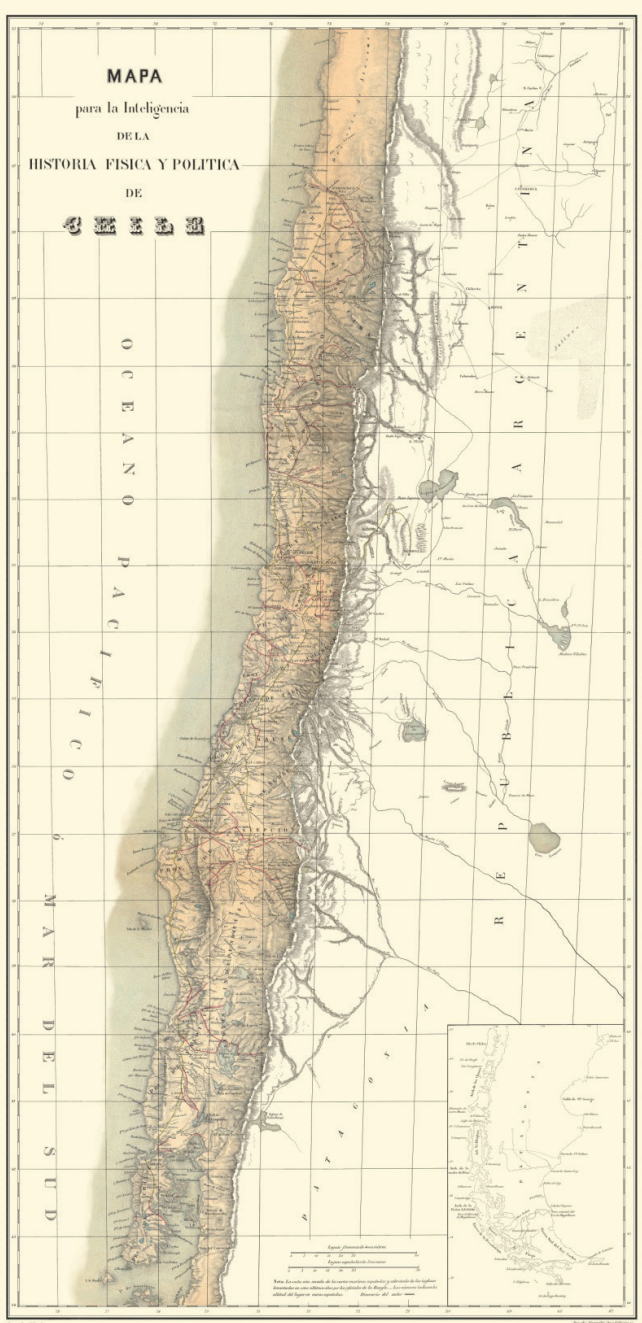

Fuente: Gay, 1854.

Fue la sistemática exploración del territorio nacional, y el consiguiente reconocimiento de sus componentes naturales y humanos, emprendida por científicos a lo largo del siglo XIX, lo que hizo posible también completar el proyecto político nacido junto con la independencia, asegurando así el futuro de la nueva entidad soberana.

Propósito que tuvo en la cartografía de Claudio Gay una original y elocuente manifestación, entre otras razones, por ser el primero en representar "científicamente" el territorio chileno en los primeros años de la república; es decir, el que se extendía entre los $26^{\circ}$ y $44^{\circ}$ de latitud sur y los $71^{\circ}$ y $74^{\circ}$ de longitud oeste, y que es el que ilustra el "Mapa de Chile levantado por el gobierno de esta república por Claudio Gay", datado en 1841. Y en el que, utilizando la técnica del achurado, se 
identifica además la cordillera de los Andes como el elemento característico del relieve chileno. Forma, en el mapa, asociada a otras referencias naturales como ríos, cerros, islas, lagos y formas del litoral. Ofreciendo también una toponimia esencial que, como aseguró Gay, indicaba "la posición relativa de los parajes".

Un trabajo preparado por el naturalista durante sus exploraciones, siempre provisto de un círculo de reflexión, de un anteojo astronómico de Robert Cauchoix y de tres buenos cronómetros, instrumentos que le habían permitido, como escribió Gay al ingeniero geógrafo del Instituto de Francia, Edme François Jomard, "determinar la latitud y longitud de los principales puntos que he coordinado después por triangulaciones magnéticas". Resultando un mapa que, aseguró, "difiere de todos los que se han publicado hasta el presente" (Feliú Cruz y Stuardo Ortiz, 1962: 16).

\section{Ciencia republicana}

En los inicios de la república, cuando todo estaba por hacerse, cuando Chile sólo existía como proyecto institucional, ¿cómo era el territorio bajo la jurisdicción del nuevo Estado?, ¿cuáles eran las características físicas, económicas, culturales y sociales del conjunto bajo su soberanía?, ¿qué noción había acerca del número y distribución espacial de sus habitantes? ¿cuáles eran sus principales recursos económicos, las especies vegetales y animales?, ¿cuáles sus características ambientales?, ¿sus potencialidades? A éstas, y muchas otras interrogantes buscaba dar respuesta el gobierno chileno cuando en 1830 decidió la contratación de un naturalista que, gracias al conocimiento generado por la ciencia, pudiera resolver las cuestiones planteadas, y así hacer posible la existencia independiente del nuevo Estado.

Con los conocimientos que Claudio Gay generó sobre la historia, el territorio y el mundo natural y cultural del país, contribuyó decididamente al proceso de organización republicana y consolidación de la nación, dando forma así a una realidad que hasta entonces sólo permanecía como proyecto, en potencia.

La monumental "Historia física y política de Chile" de Claudio Gay, publicada en 30 volúmenes entre 1844 y 1871, no sólo resumió el conocimiento existente sobre Chile en la época, lo cierto es que a partir de ella se realizaría el trabajo de los científicos que como Ignacio Domeyko, Rodulfo Philippi, Amado Pissis y Hans Steffen, entre muchos otros, lo sucedieron en la tarea de explorar, estudiar, inventariar y proyectar Chile, que no otro es el papel que cumplió la ciencia.

Esta verdadera gesta del conocimiento hizo posible dar forma, delinear un territorio, una república y una nación, reflejando la trascendencia de la investigación científica. Gracias a ella es que Chile también tuvo identidad, contenido, rasgos definidos, densidad conceptual, incluso una representación como comunidad (Sagredo Baeza, 2004).

En medio de las limitaciones de la época, con un panorama financiero realmente dramático, los organizadores de la república tuvieron la visión y el valor de invertir y promover la ciencia, la ciencia básica, la investigación. Tuvieron el atrevimiento de soñar, de pensar, de imaginar un país posible. Y fue producto del trabajo científico que Chile dilató su territorio, reconoció y apreció sus recursos naturales e hizo posible su desenvolvimiento económico. Pero, sobre todo, fue gra- 
cias a la ciencia que se crearon los lazos que hicieron posible su viabilidad como sociedad, como comunidad, como nación. La investigación científica, el trabajo intelectual y la creación artística, resultaron instrumentos imprescindibles en este proceso de hacer posible una realidad llamada Chile, a partir de la cual se pudo planificar el futuro de la comunidad que la conforma; aprovechar las riquezas naturales existentes en su territorio; y enfrentar creativamente los desafíos que le imponen el medio y su evolución histórica.

\section{Chile antes del mapa de Chile}

Entre los estímulos que el gobierno tuvo para contratar a Claudio Gay en 1830, determinante fue el relacionado con la posibilidad de contar con una cartografía fiable de Chile, entonces inexistente. Como en muchos otros campos, fue durante la etapa de la organización de la república que se había advertido la necesidad de contar con mapas del territorio, e incluso emprendido iniciativas destinadas a la elaboración de los mismos. Entre ellas está el decreto de Ramón Freire del 26 de junio de 1823 que, fundado en "la necesidad de reunir toda clase de datos estadísticos que dirijan al gobierno en las providencias que debe tomar para promover la prosperidad nacional", determinó la realización de "un viaje científico por todo el territorio del Estado" destinado a examinar la geología del país, sus minerales y demás materias propias de la historia natural. Fue entonces que se comisionó a Juan José Dawson Lavaysse para emprender la tarea (Sesiones de los cuerpos legislativos, en adelante SCL, VII, 1889: 312). Meses después, el 20 de diciembre del mismo año, y como complemento del viaje científico, el mismo gobierno mandó levantar una carta geográfica del país.

La necesidad de cartografía se fundamentaba en la "diaria experiencia del gobierno" relacionada "con los embarazos que se presentan para dirigir la administración civil y militar y dar un impulso activo a la industria, y al buen orden y economía interior de los pueblos, sin que exista un buen mapa de su territorio". Pero también en la urgencia de cumplir con el mandato del Congreso Constituyente de promulgar una división político administrativa "luego de que se hayan procurado los datos necesarios para verificarla cómoda y provechosamente".

La falta de conocimientos geográficos sobre el territorio del Estado y la absoluta ignorancia sobre su número de habitantes y distribución era reconocida también por el Congreso Nacional. Reflejo de esta realidad es la conclusión a la que llegó la instancia formada en 1823 para demarcar y dividir el Estado. En ella se lee que sus integrantes "no han dudado un solo momento para opinar que la predicha partición debe practicarse tan pronto como pueda hacerse; pero cree que no habiendo hasta hoy planos geográficos y topográficos del país, la estadística general de él, ni aun siquiera un conocimiento aproximado de la población, producciones y arbitrios de cada uno de los partidos en que ha de dividirse, es muy aventurada cualquiera división que se adopte" (SCL, VIII, 1889: 205).

Fundado en estos antecedentes, el Director Supremo decretó que "inmediatamente se dará principio a la formación de un mapa corográfico de Chile", confiando la empresa al ingeniero militar José Alberto D’Albe y al ingeniero geógrafo Carlos Ambrosio Lozier (Barros Arana, 1911: 239-457). 
Frustradas estas iniciativas, entre otras razones por la incapacidad de los comisionados y la inestabilidad institucional, sólo a comienzos de la década de 1830 volvió a presentarse la oportunidad de materializarla. Ahora, gracias a la presencia de una persona idónea, Claudio Gay, y un gobierno capaz de sustentarla, el establecido luego de las luchas del año 1829 que llevó al poder a los conservadores encabezados por Diego Portales.

En su plan de trabajo presentado en julio de 1830, el naturalista ofreció levantar "planos de las principales ciudades y ríos y de todas las haciendas que pueda visitar", oferta que en el contrato que firmó con el gobierno en septiembre siguiente se transformó en la obligación de levantar "cartas geográficas de cada una de las provincias y de vistas y planos de las principales ciudades, puertos y ríos" (Stuardo Ortiz, 1973: 89-91.). Hasta entonces, prácticamente la única cartografía geográfica e hidráulica existente era la preparada por la Expedición Malaspina en la década de 1790, principalmente costera, con numerosas inexactitudes y pocos puntos determinados astronómicamente.

Por eso es que la preparación de un mapa de Chile, que Gay se comprometió a publicar "en grande escala", junto con un atlas con "el mapa de cada una de las provincias", fue una de las tareas que inició desde el momento mismo de su llegada cuando, gracias a sus excursiones por el espacio adyacente a Santiago y estudios en diferentes fuentes, delineó "el plano de la ciudad y cartas geográficas de Chile propiamente dicho", como "del país habitado por los araucanos".

Aunque los afanes republicanos por conocer los territorios sobre los que comenzaban a ejercer soberanía están estrechamente relacionados con los intereses del Estado nacional, fueron también una herencia del espíritu ilustrado que, a lo largo del siglo XVIII, había llevado a las potencias europeas a organizar, financiar y promover expediciones científicas a suelos y costas americanas, entre otras razones, para obtener ventajas económicas de ellos. Por eso es que desde 1700 en adelante América fue visitada por numerosos científicos que la exploraron, midieron, censaron, describieron, representaron y proyectaron. Motivados por la competencia imperial, la necesidad de descubrir y aprovechar nuevos recursos y riquezas, los afanes de gloria nacional y las necesidades de la ciencia, España, Francia, Inglaterra, Portugal y Prusia recorrieron América, ahora, por intermedio de comisiones científicas que identificaron especies, censaron poblaciones, registraron fenómenos geográficos y señalaron características de las regiones exploradas (Sagredo Baeza y González Leiva, 2004).

Entre las empresas ilustradas, la Expedición Malaspina que recorrió América y el Pacífico entre 1789 y 1794, legó una abundante cartografía que, para el tema que nos ocupa, tiene algunas particularidades. En efecto, entre una gran cantidad de vistas de la costa y representaciones del litoral sur occidental americano, destaca la "Carta esférica de la parte interior de la América Meridional para manifestar el camino que conduce desde Valparaíso a Buenos Aires, construida por las observaciones astronómicas que hicieron en estos parajes $D^{\circ}$ José de Espinoza y $D^{\circ}$ Felipe Bauzá, oficiales de la Real Armada en la Dirección Hidrográfica. Año 1803".

Esta representación, que abarca una franja de $9^{\circ}$ en latitud y $16^{\circ}$ en longitud y que tiene como eje este-oeste las ciudades de Valparaíso por el occidente y Buenos Aires por el oriente, tuvo como fin cartografiar el camino que cruzaba la cordillera de los Andes y unía la vertiente occidental con la oriental del macizo andino. Sin embargo, y más allá de su objetivo inmediato, este mapa 
ofrece con mucha claridad la concepción geográfica existente durante la Colonia, por lo menos respecto de los territorios localizados en el sur occidente de América.

Se trata de un espacio integrado por diversas regiones que se ordenan horizontalmente, en sentido este-oeste, y que, como en el caso de la carta mencionada, muestra una concepción trasatlántica de las posesiones coloniales. Como se comprenderá, entonces éstas obedecen a una lógica imperial en la que todos los territorios que más tarde formarán los espacios nacionales, separándose uno de otros, todavía aparecen integrados en función de circuitos y flujos comerciales. La república, la nueva realidad política, precisará de cartografía orientada por los intereses nacionales.

Figura $\mathrm{N}^{\circ} 3$

"Carta esférica de la parte interior de la América Meridional para manifestar el camino que conduce desde Valparaíso a Buenos Aires, construida por las observaciones astronómicas que hicieron en estos parajes $D^{\circ}$ José de Espinoza y $D^{\circ}$ Felipe Bauzá, oficiales de la Real Armada en la Dirección Hidrográfica.

Año 1803"

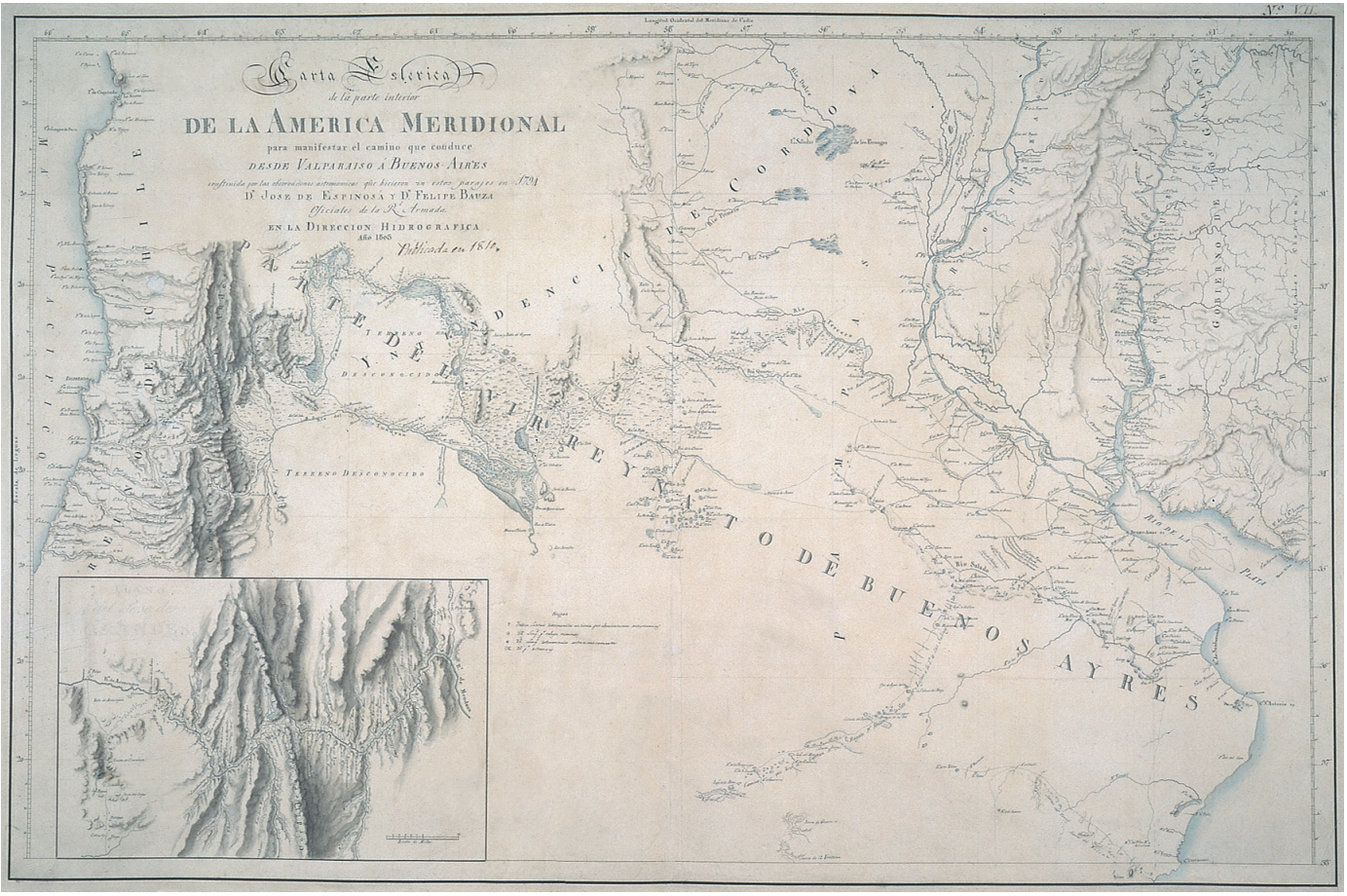

Fuente: Museo Naval de Madrid.

\section{Naturalistas en América}

El quehacer de los naturalistas, las exploraciones geográficas y las representaciones cartográficas de los territorios de los estados nacidos con la independencia facilitaron notablemente la materialización de algunos de los procesos fundamentales que se desenvolvieron luego de 1810 en América, entre ellos: la organización de las repúblicas, la consolidación de los estados, el ejercicio de la soberanía, la inserción en los mercados internacionales y la formación de las naciones. 
Exploradores como Agustín Codazzi, Alcide d'Orbigny, Claudio Gay, V. Martin de Moussy, Germán Burmeister, Dámaso Larrañaga o Antonio Raimondi, por nombrar algunos de los que recorrieron países americanos, al describir precisa y exactamente los territorios de Venezuela, Nueva Granada, Bolivia, Chile y Perú, contribuyeron a la creación y consolidación, desde el conocimiento científico, de estas repúblicas sudamericanas que, además, definieron entusiastamente. Demostración de ello son el "Resumen de la geografía de Venezuela" de Codazzi, la "Descripción geográfica, histórica y estadística de Bolivia" de d’Orbigny, la "Historia física y política de Chile" de Gay, la "Description Géographique et Statistique de la Confédération Argentine" de de Moussy o "El Perú" de Raimondi; todas, verdaderos certificados de identidad de las nuevas repúblicas, a la vez que fundamentos científicos e intelectuales de las respectivas naciones. En estas obras, las descripciones de los espacios bajo la soberanía del nuevo Estado, y las representaciones cartográficas que ellas permitieron elaborar, constituyen elementos esenciales del proceso de representación, conocimiento y control de los territorios de los noveles estados.

No cabe duda de que con su trabajo los naturalistas proporcionaron a los nuevos estados la justificación material de su existencia gracias a la identificación de sus recursos naturales y, con ello, la legitimación científica de su viabilidad económica.

Desde 1810 en delante, y en la mayor parte de los países latinoamericanos, el Estado se preocupó de explorar y cartografiar su territorio, existiendo plena conciencia de la necesidad de conocer el espacio sobre el cual ejercían soberanía. Para el caso chileno, entonces ni siquiera existían mapas medianamente aceptables; poco se sabía de la situación exacta de las ciudades y puntos geográficos de importancia; nadie había estudiado sistemáticamente las especies naturales; y, menos aún, preocupado de las características geológicas o de precisar adecuadamente las condiciones climáticas de los ambientes en que comenzaba a desenvolverse la nueva república.

En Venezuela Agustín Codazzi es apreciado como el geógrafo que elaboró los primeros mapas de aquel país, tanto como su primera descripción sistemática. De ahí que se le valore por su aporte "a la construcción de Venezuela como nación independiente". Pero también por haber "prefigurado la reorganización del territorio de Venezuela aprovechando plenamente sus recursos naturales" (Pérez Rancel, 2006: 9-10).

Respecto de Colombia, su obra "marcó el comienzo de la aproximación sistemática al conocimiento físico" de esta república, y su Comisión Corográfica se distingue por su carácter integral, como por la descripción metódica de un país en todas sus facetas. El valor de su obra no sólo ha sido aquilatado en relación al conocimiento propiamente científico, también en función de la política e identidad nacional colombiana. El italiano contribuyó decisivamente a la integración nacional a través de la consolidación de la "imagen de Colombia como nación unitaria y con identidad propia", y su labor en América permite afirmar que sus trabajos en Venezuela y Nueva Granada "fueron los primeros estudios geográficos sistemáticos a nivel nacional en América del Sur" (Sánchez, 1998 y Appelbaum, 2017).

La acción de Alcide d'Orbigny en Bolivia entre 1830 y 1833 se materializó en su monumental obra "Voyages dans l' Amérique méridionale" y en otros escritos como "L' Homme Americane" y "Descripción geográfica, histórica y estadística de Bolivia", todas las cuales lo transformaron en el hito fundamental de la ciencia boliviana. Fue el primero en describir, con una amplia y multidisciplinaria perspectiva, la Bolivia de los inicios de la república, "estudiando en ella prácticamente 
la totalidad de sus múltiples y complejas facetas", siendo su obra "la más grande contribución al conocimiento de las riquezas naturales del país" (Arce Aguirre, 2002: 16 y 35).

Antonio Raimondi llegó a Perú en 1850 para "dar a conocer específicamente las riquezas naturales de un país que otros investigadores sólo habían esbozado genéricamente" (Villacorta, 2003: 29). Después de ocupar diecinueve años en recorrerlo, en lo que se valora como la prospección científica más ambiciosa, completa, sistemática y dilatada que se haya realizado en algún territorio americano en la segunda mitad del siglo XIX, legó a su patria adoptiva una obra en que "el ámbito nacional adquiere por primera vez una cohesión fundamentada en contundentes apreciaciones científicas, las que sintetizan la primera visión completa de nuestro país" (Villacorta, 2003: 32). Gracias a la obra del italiano, y como nueva muestra del relevante papel de los naturalistas en la América del siglo XIX, el territorio peruano se transforma en país y la diversidad cultural deviene en nación; surgiendo el Perú con todas las características que determinan su identidad (Villacorta, 2010).

Al igual que otros desde Alexander von Humboldt en adelante, Raimondi también se esforzó por representar cartográficamente el espacio en que se desenvolvió como científico. Al mapa de Perú, la carta nacional editada en 1890, destinó parte importante de su tiempo, demostrando así que captó lúcidamente la importancia de los mapas en el desenvolvimiento nacional en tanto instrumento de cohesión política y social; además de facilitar la planificación y ejecución de cualquier proyecto público o privado.

El estudio de la obra cartográfica del naturalista Claudio Gay sobre Chile muestra que ella se transformó en un aporte sustantivo al conocimiento geográfico de la nueva república, en instrumento fundamental de la administración estatal y en herramienta invaluable de la integración territorial de la sociedad que, a lo largo del siglo XIX, se consolidó como Estado y nación. Entre otras razones, por la efectiva representación gráfica que difundió a través de las láminas geográficas de su "Atlas de la Historia física y política de Chile", todas, verdadero programa de acción para el Estado chileno.

\section{Chile explorado y esbozado}

El arribo de Claudio Gay al país en los primeros días de diciembre de 1828 fue consecuencia de su contratación como profesor del Colegio de Santiago, cuyas actividades docentes se iniciarían en marzo de 1829. El naturalista, que lograría fama gracias a sus investigaciones sobre Chile, había nacido en marzo de 1800 en Draguignan, departamento del Var, en la Provenza, en medio de una familia de pequeños propietarios agrícolas (Sagredo Baeza, 2007).

El celo y la pasión que Gay mostraba por la historia natural, expresada en su infatigable actividad y dedicación al estudio, no sólo llamaron la atención de los pocos sujetos con interés por las ciencias naturales existentes en Santiago. También llegó a conocimiento de las autoridades, en las cuales rondaba la idea de estudiar científicamente el país, una antigua aspiración que no había podido materializarse por falta de una persona idónea para acometer la empresa. En el Chile de la organización republicana, donde todo estaba por hacerse, y aun en medio de las tribulaciones políticas y la pobreza del erario, hubo sujetos en el Estado que tuvieron plena conciencia de la necesidad de conocer cabal y científicamente el territorio y la realidad nacional. 
Alentado por sus cercanos, en julio de 1830 Gay redactó una presentación dirigida al Vicepresidente de la República a través de la cual ofreció sus servicios para trabajar en la preparación de una historia natural, general y particular de Chile; una geografía física y descriptiva del país; una geología que haría conocer la composición de todos los terrenos, la estructura de las rocas y la dirección de las minas; y una estadística completa de las actividades productivas y de la población. Además de los trabajos nombrados, el científico se comprometió a elaborar cuadros estadísticos de todas las provincias; hacer un catálogo de todas las minas; y a preparar planos de las principales ciudades y ríos, así como de todas las haciendas que pudiera visitar. Es decir, Gay se obligó a una tarea monumental, la cual le llevaría casi toda la vida.

Atendidos los antecedentes, no debe extrañar que en septiembre de 1830 se autorizara al ministro del Interior, Diego Portales, para suscribir un contrato con Gay en virtud del cual quedaría sellado el viaje científico por el territorio. Como justificaciones se esgrimieron, tanto la importancia de la iniciativa, como las cualidades de Gay para verificarlo con ventaja para el país.

Concluidos los trámites administrativos y los preparativos indispensables para emprender el viaje científico, Gay se dispuso a acometer la exploración del territorio nacional, tarea que inició por la provincia de Colchagua en diciembre de 1830. Desde entonces, y hasta 1842, exploró el territorio nacional entre Atacama y Chiloé, identificando y caracterizando acabadamente las propiedades del espacio natural que ocupaba el país. Con su acción, y aplicando el conocimiento que le dieron sus viajes, siguió el modelo geográfico señalado por Alexander von Humboldt, describiendo el espacio natural a partir de los elementos que lo distinguían que, en este caso, resultó en la creación de Chile, tanto en su condición de unidad natural como política. No por nada Claudio Gay escribió que, si el globo se dividía en regiones en razón de la apreciación de los géneros y especies peculiares a cada una de ellas, "ningún país más digno de ser elevado al título de región que la república de Chile. Perfectamente limitado por barreras infranqueables"4.

En el cumplimiento de su comisión, desarrolló un patrón de conducta que cumplió rigurosamente durante sus excursiones, y que explica el éxito final de su empresa científica. En cada lugar que visitó o recorrió, procedió a examinar y estudiar las especies naturales, recolectando todas aquellas que le resultaban de interés. Fijar con exactitud la situación de los puntos geográficos, auxiliado por los modernos instrumentos adquiridos en Europa, fue también objeto de su atención. Los estudios geológicos y el levantamiento de la respectiva carta geográfica de la zona visitada constituyeron otras de sus ocupaciones permanentes. La recopilación de estadísticas, de documentación y de todo tipo de noticias de los parajes y poblados recorridos, fueron también sus actividades características. Observaciones climáticas y sus mediciones meteorológicas, así como las destinadas a determinar el magnetismo terrestre, fueron otra constante de su acción. Por último, el dibujo, la preparación de bocetos, delinear accidentes geográficos y tomar vistas de paisajes y sujetos, ocuparon también su tiempo y fueron la base de su "Atlas".

En su afán por cartografiar Chile el naturalista tuvo especial preocupación por representar los espacios interiores del país, los alejados del litoral del océano Pacífico. Si, como afirmó, "Chile no posee más cartas geográficas que las de la costa", siendo las del interior "muy imperfectas y la más de las veces formadas sobre datos absolutamente falsos", se comprenderá su interés por

Véase su texto "Fragmentos de geografía botánica de Chile", ca. 1854, en Stuardo Ortiz, II, p. 318-329. 
levantar una carta geográfica que comprendiera Chile central ${ }^{5}$. El inmediatamente adyacente a los Andes, aquel en el cual nacían y corrían los ríos, se levantaban los volcanes y se ubicaban los lagos, entre otros muchos elementos naturales imprescindibles de localizar para el adecuado conocimiento geográfico del territorio chileno.

Comprendiendo el valor de sus representaciones, más de una vez explicó que durante sus excursiones se propuso averiguar la posición relativa de los parajes que le eran conocidos o que nombraban sus guías; determinar la posición de los puntos más señalados; establecer los límites de las provincias; dar a conocer el origen, dirección y extensión de los ríos, entre otros objetivos destinados a perfeccionar los mapas del país. Una tarea que definió como un "trabajo de gran utilidad" para las operaciones administrativas del gobierno ${ }^{6}$.

En el informe presentado luego de su viaje a Valdivia y Chiloé, Gay escribió que, de todos sus afanes, "el que considero de una utilidad superior es el relativo a la geografía de la república"7. Entre otras razones, porque "desde mis primeras observaciones a este respecto he visto cuán falsas y casi indignas de la crítica han sido las cartas de Chile publicadas hasta la fecha"

Errores groseros, vacíos e inexactitudes, especialmente de la parte interior del territorio y en los pormenores de las representaciones, eran los más comunes. Así, por ejemplo, y para demostrar su evaluación, Gay relata que "en las cartas más recientes, y hasta en las publicadas en 1836, en la provincia de Valdivia la ciudad de Osorno, tan conocida, se halla constantemente colocada sobre un inmenso lago que jamás ha existido, a menos que se haya querido indicar el Llanquihue, casi enteramente desconocido antes de mi visita y situado a más de veinte leguas de esta población".

Hacia 1836 ya tenía avanzados algunos levantamientos cartográficos, según se deduce de las noticias que entrega en las crónicas sobre sus excursiones por las provincias; incluso tiene muy adelantado un borrador del mapa de Chile, el cual estaba siendo preparado a partir de representaciones parciales, como la que mostraba el espacio entre los ríos Maule e Itata, en el cual ya se insinúan los contenidos que tendrán sus mapas definitivos, tanto como el Chile que se proyectaba.

Sería el trabajo acumulado a lo largo de más de una década lo que le permitió hacer llegar al gobierno "una carta que desde todo punto de vista debe merecer toda su confianza", como le recordó a Manuel Montt en 1843, asegurándole que la misma "es bastante exacta y más que suficiente para cualquier operación administrativa"9.

Tanto en el borrador de mediados de la década de 1830, como en el que llamó "mi gran mapa", Gay ofrece la representación esencial de lo que terminaría siendo Chile republicano. No sólo porque presenta el espacio comprendido entre la cordillera y el mar, entre el desierto de Atacama y

"Viaje científico. Segundo informe sobre sus exploraciones en la provincia de Colchagua", en Stuardo Ortiz (1973), tomo II, p. 103.

Véanse los informes sobre sus viajes a las provincias de Valdivia y Chiloé de julio de 1836 y de Coquimbo de febrero de 1837, en Stuardo Ortiz (1973), II, p. 209 a 219.

"Viaje científico. Estudios realizados en las provincias de Valdivia y Chiloé", Santiago, 4 de julio de 1836, en Stuardo Ortiz (1973), II, p. $210-212$.

Sobre este punto, véanse el informe sobre su segundo viaje científico a Colchagua de abril de 1831, o la reseña acerca de sus investigaciones en Chile presentada a la Academia de Ciencias de París en marzo de 1833; ambos en Stuardo Ortiz (1973), t. II, p. 103 y 162.

9 Véase su correspondencia a Manuel Montt fechada el 20 de enero y el 15 de mayo de 1843, en Feliú Cruz y Stuardo Ortiz (1962), p. 48 y p. 52. En septiembre de 1841, en nota a Montt fechada el 11, había dado por acabada la carta de Chile. 
Figura $\mathrm{N}^{\circ} 4$

Borrador de Claudio Gay de la zona comprendida entre el río Maule y el río Itata

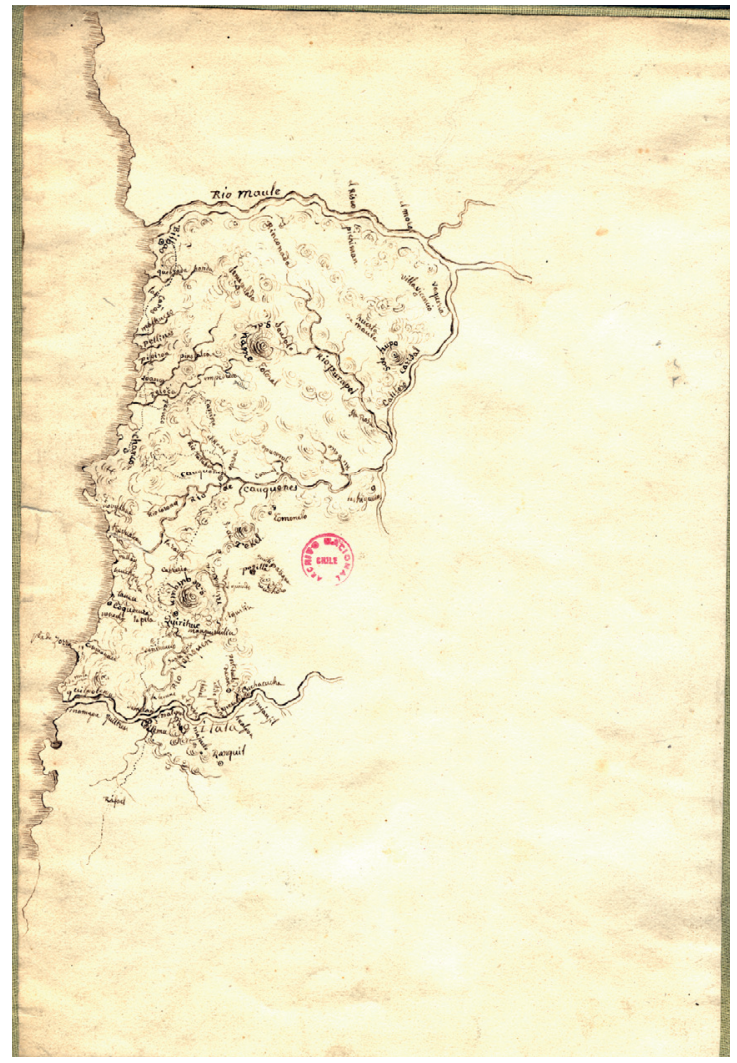

Fuente: Archivo Nacional Histórico.

Chiloé, los límites naturales del país; porque identifica los principales accidentes geográficos del territorio, como sus ríos, cumbres, bahías y puntos salientes del litoral; o porque al margen señale paralelos y meridiano y los nombres de las divisiones político-administrativas, y en su interior las poblaciones más importantes; sobre todo, porque era la primera vez que se mostraba Chile como llegaría a ser; como la realidad, apreciada por Gay en terreno, indicaba que debía ser, esto es, una unidad geográfica orientada de norte a sur, integrada por el eje que su gran desarrollo latitudinal haría posible, y que hacía del centro, de Santiago, la base de cualquier posible iniciativa, fuera esta gráfica o política. De este modo el boceto y el mapa de 1841 no sólo son adelantos de un mapa definitivo por publicarse, son, sobre todo, interpretamos, el proyecto estatal y nacional por cumplirse a partir de entonces y que la representación de Gay fijaba en el papel de una manera que lo dejaba al alcance de todos por la efectividad de la imagen y la elocuencia de su contenido.

La condición de borrador del mapa remitido al gobierno no sólo se constata en su materialidad, también en la superficie representada. Y así se puede apreciar con la simple comparación con el que terminaría publicándose en 1854. El contraste permite valorar la efectividad del trabajo del naturalista y la agudeza de su propuesta para el futuro de Chile, consecuencia de su experiencia en terreno y, por lo tanto, de la realidad que él supo captar y llevar al impreso. 
Figura $\mathrm{N}^{\circ} 5$

"Mapa de Chile levantado por orden del gobierno de esta república por Claudio Gay, 1841"

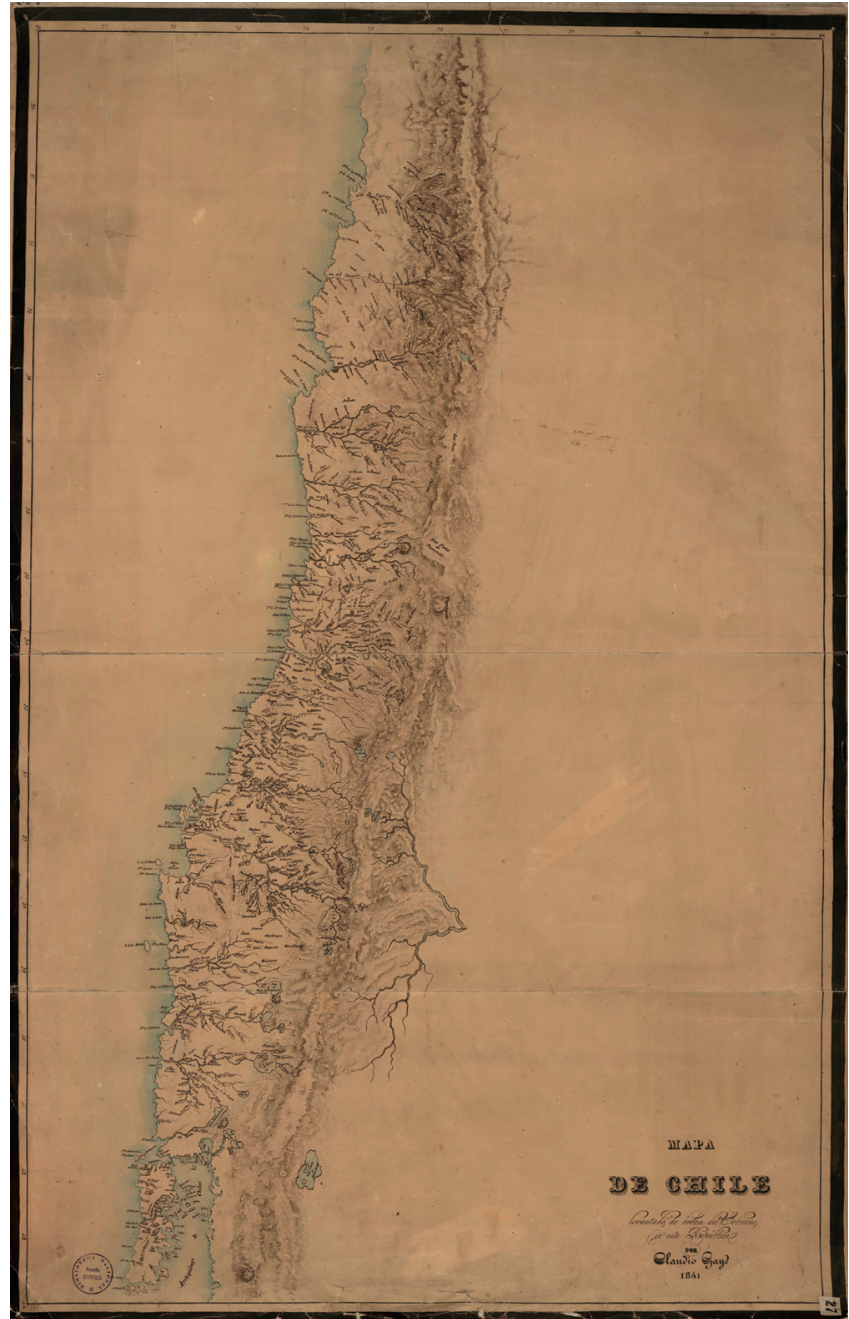

Fuente: Biblioteca Nacional de Chile.

\section{Chile cartografiado y proyectado}

Claudio Gay incluyó quince mapas en su Atlas, éstos representan Chile en general, las diferentes provincias y algunos de los principales hitos geográficos. Su sola existencia, además de facilitar la historia de la cartografía nacional y enseñar acerca de la conformación política y administrativa de la joven república, muestra la trascendencia que el Estado de la época le asignó a la información geográfica y el valor que Gay le atribuyó para la comprensión de su trabajo.

No puede existir otra explicación para que incluyera dichas cartas, y que en ellas se ocupara de algunos accidentes específicos, como el estrecho de Magallanes, las islas de Juan Fernández 
o el archipiélago de los Chonos, todas unidades geográficas de gran importancia para la época como se deduce de su presencia en el "Atlas". Más todavía, la inclusión, como imagen inicial, de una lámina gigante que debe desplegarse para ser observada, que Gay nombra "Mapa para la inteligencia de la Historia Física y Política de Chile", y en la cual se representa por primera vez todo el país, muestra el afán del naturalista por ofrecer una visión completa del Chile de entonces, en este caso, a través de su presentación in extenso.

La importancia de este mapa se puede apreciar desde numerosas perspectivas. En primer término, por su valor en tanto representación geográfica del territorio chileno en una época en que las mismas son prácticamente inexistentes y poco confiables. Precisamente porque Gay quería hacer saber de la seguridad que su mapa podía ofrecer, es que coloca como nota en el mismo que éste había sido preparado sobre la base de cartas españolas e inglesas "levantadas en estos últimos años".

Más trascendente resulta que en el mapa se ofrezca la visión existente en el Chile del siglo XIX sobre los espacios que conformaban su territorialidad. En efecto, en la carta sólo está representada la superficie, entre los Andes y el Pacífico, comprendida entre el desierto de Atacama y la isla de Chiloé. Es decir, un Chile ajeno, como lo era en realidad, a los inhóspitos desiertos de sus extremos y totalmente circunscrito al breve espacio que la cordillera de los Andes deja antes de alcanzar el mar; aunque con la aspiración de ejercer soberanía efectiva en la Patagonia occidental hasta el estrecho de Magallanes.

Es la materialización cartográfica de una realidad natural; Chile representado como efectivamente era. Un espacio de gran desarrollo latitudinal que el científico había logrado captar gracias a sus excursiones por el país. Un territorio que pese a su gran extensión en sentido norte sur estaba destinado a integrarse y constituirse en uno solo gracias a la acción de un Estado al que Gay, a través de su mapa, dotaba del instrumento preciso para consolidar y extender su soberanía y, de paso, contribuir a la formación de la nación.

En lo relacionado con la integración nacional, el mapa ilustra los caminos coloniales o "Camino Real" como se nombran, instrumentos esenciales para la vinculación entre las regiones del país. También ofrece los caminos que en la época permitían "pasar las cordilleras", tanto en dirección a la "República de la Plata", como en el interior del país; sin duda una inclusión fundamental en orden a dar a conocer las vías de comunicación y facilitar el tráfico, tanto de productos y bienes, como de personas. Por último, la carta muestra también el itinerario del naturalista, manifestación fehaciente de que su trabajo era fruto de la exploración, de la investigación en terreno y, por tanto, garantía de seriedad y acuciosidad científica.

La comparación entre el Camino Real y los derroteros seguidos por Claudio Gay reflejan que no se limitó a recorrer aquellos lugares y regiones más accesibles, sino que fue más allá en su afán por reconocer y describir a la naciente república.

Por último, y a diferencia del borrador que lo había precedido, el mapa de Chile incluye también un recuadro con la sección meridional de América del Sur, la llamada Patagonia, en el cual se identifican los principales puntos y accidentes geográficos de las costas, sin prácticamente ninguna referencia al interior, pues estaba destinado a ilustrar de un modo general sobre una región que para Chile resultaba de interés. 
Considerando la falta de noticias y datos sobre esas latitudes, en la representación, como en las cartas específicas de la región que forman parte del "Atlas", el naturalista se limitó a delinear los espacios continentales e identificar los fenómenos naturales costeros que le proporcionó la información existente en la cartografía española e inglesa. Esto explica que además de señalar los archipiélagos, islas, canales, cabos y bahías situados en el litoral, solo se contente con nombres muy generales para los territorios interiores, como Patagonia oriental y occidental; o, sencillamente, que nombre como "tierra desconocida" al área entre las dos "patagonias" que se extiende al sur del paralelo 47 y hasta el 52 aproximadamente.

La representación cartográfica del extremo sur de Chile y la inclusión de los archipiélagos australes, estrecho de Magallanes incluido, obedeció a una decisión política más que científica, pues el naturalista no sólo jamás alcanzó hasta esas latitudes, sino que además eran espacios desconocidos, no integrados al territorio chileno o a cualquier otro. La inclusión en sus mapas debe considerarse una forma de reafirmar las reivindicaciones chilenas sobre aquellas regiones, las cuales, en la década de 1840, ya se habían materializado en actos de soberanía ${ }^{10}$.

De este modo, los mapas de América meridional del científico no sólo ilustraban sobre una región remota y desconocida desde el punto de vista geográfico, además de ajena a toda manifestación política o administrativa de gobierno alguno; en realidad, la transformaban en chilena por el solo acto de representarla en la primera cartografía nacional.

Completando lo que en el borrador de Chile había sido sólo una mención en los márgenes de la representación, el "Atlas" incluye cartas de cada una de las provincias supuestamente existentes. Son nueve mapas con las unidades político administrativas delineadas por la nueva república que hasta ese momento nunca antes se habían representado, y que mostraban las provincias que sucesivamente se habían ido creando desde 1812 en adelante, hasta completar 13 en 1853. Ordenadas de sur a norte, el científico ofrece los mapas de Chiloé, Valdivia, Concepción, Cauquenes, Talca y Colchagua, Santiago y Valparaíso, Aconcagua, Coquimbo y Atacama.

Si bien las representaciones cartográficas no corresponden exactamente a las divisiones político administrativas existentes, pues no aparecen las provincias de Maule, Nuble y Magallanes y jamás existió la que nombra Cauquenes, lo cierto es que de todas formas la obra representa un hito al mostrar el territorio de Chile ordenado por el Estado en uso de sus facultades soberanas"1. En estas cartas están los principales hitos de cada división político administrativa, como lo son los límites provinciales y departamentales, las poblaciones, las capitales y las vías de comunicación. Pero también los fenómenos geográficos más señalados contenidos en cada una de ellas, como ríos, cerros, lagos, islas y, en general, las formas del litoral.

En virtud de todo lo anterior, y más importante todavía, en cada uno de sus mapas ofreció información geográfica que va más allá del litoral oceánico y los espacios inmediatos a él. Gracias

\footnotetext{
En 1843 se había tomado posesión efectiva del territorio adyacente al Estrecho de Magallanes a través de la fundación de una población llamada Fuerte Bulnes. Para el gobierno y la opinión pública de la época, el control del Estrecho era de importancia fundamental en razón de las posibilidades de contacto con Europa.

11 Una explicación posible para las inexactitudes o vacíos de la cartografía provincial del Atlas puede encontrarse en el hecho de que Gay sólo permaneció en Chile hasta 1842, cuando todavía no se creaban las provincias de Atacama, Ñuble y Magallanes y, obviamente, no recibió la información precisa.
} 
a sus excursiones pudo identificar, nombrar y situar las poblaciones, formas y unidades naturales existentes al interior del territorio, ensanchándolo respecto de la época colonial, contribuyendo no sólo a delinear el espacio nacional, también a configurarlo al darle un contenido preciso, reconocible e identificable.

Considerando que nunca se había levantado una carta geográfica del interior de Chile, el conjunto de representaciones cartográficas del naturalista le dio profundidad espacial al territorio nacional al expandir su mirada más allá de las formas de las costas del Pacífico. Por el solo hecho de situar y representar la realidad cultural y natural de los espacios que se extendían hasta los Andes, lo dilató en sentido este-oeste, contribuyendo así a su identificación como unidad geográfica, pero también política.

En términos de la noción geográfica de Chile, interesante resulta advertir que los mapas de las provincias de Cauquenes, Talca, Colchagua, Santiago y Valparaíso aparecen, en especial las tres primeras, en representaciones con una disposición este-oeste y no norte-sur. En el Chile de entonces, en proceso de organización y consolidación nacional, Claudio Gay percibe que en algunas zonas aún prevalece el ordenamiento espacial colonial en función de ejes horizontales o transversales marcados por el curso de los ríos que van de la cordillera al mar. Éstos determinan y organizan un espacio regional que gracias a los trabajos del científico comenzará a transformarse dando paso al proceso de unificación territorial del Estado y la nación que desestructurará los ejes regionales horizontales en favor de un solo eje vertical, norte-sur, una de cuyas expresiones intelectuales es el mapa de Claudio Gay y, más tarde, el ferrocarril longitudinal. Sin duda una manifestación geográfica de la consolidación y del dominio del Estado centralizado sobre el territorio y, por tanto, también, de construcción de la nación.

Otra muestra del peso del pasado en la sociedad chilena de la época en que Claudio Gay vivió en Chile es que en sus mapas apenas existe el océano Pacífico, el que sólo una vez aparece con ese nombre, manteniendo el naturalista, cada vez que alude a ese espacio marítimo, el nombre de Mar del Sur, como era conocido durante la Colonia, pues así lo habían llamado los españoles. Reflejo a su vez de otra de las características de la sociedad chilena, su casi absoluta indiferencia por el mar y sus posibilidades. Resultando que en la monumental obra de Gay sobre Chile, el Pacífico y sus componentes naturales, especies, corrientes, vientos y mareas, entre otros, para no referir el patrimonio cultural que lo refleja, son prácticamente inexistentes. Prolongándose en el papel una realidad que ni siquiera el agudo naturalista pudo mostrar pues, en definitiva, no existía como objeto de interés, como realidad social y cultural.

Claudio Gay pudo delinear cartográficamente Chile pues lo había estudiado exhaustivamente, identificado como una realidad geográfica y caracterizado en sus rasgos más sobresalientes desde el punto de vista ambiental. Así se puede apreciar en la sección destinada a la historia natural de su "Historia física y política", donde abordó el estudio de la flora y fauna del país bajo los rótulos de botánica y zoología, sosteniendo que Chile sobresalía porque tenía un carácter particular derivado de las barreras naturales que cerraban todo su contorno"12.

12 Véase "Fragmentos de Geografía botánica de Chile", en Stuardo Ortiz, II, p. 318-329. 
Identificado como unidad física y política, con los Andes como referencia fundamental, Chile fue divido en regiones geográficas. A partir de las características del paisaje y de la vegetación el sabio diferenció tres zonas: Norte, Centro y Sur; dando origen a las regiones que, desde entonces, y con leves variantes, se han utilizado para dividir geográficamente el país, y a partir de las cuales se han trazado, en más de una ocasión, las divisiones político administrativas, y con ella organizado la representación política nacional (Sagredo Baeza, 2017: 783-792).

Claudio Gay representó cartográficamente una situación que ya operaba a nivel de noción de lo que era, o debía ser, Chile nacional: el estrecho espacio entre cordillera y mar situado en la vertiente sur occidental de América del Sur que, por su magnitud y orientación norte sur, prácticamente hacía desaparecer los accidentes que, como la isla de Chiloé, no formaban parte de ese eje latitudinal.

Con sus trabajos y representaciones cartográficas, el científico galo contribuyó a configurar el espacio de la nueva república, pero también a asentar la noción de territorio nacional. En este proceso, además, lo dilató, como la inclusión en sus mapas de la zona de los archipiélagos australes lo demuestra. En el camino, al privilegiar lo nacional por sobre lo local, terminó transformando la geografía al diluir en el conjunto nacional los espacios regionales coloniales.

El uso de la cartografía para la creación de Chile como nación no fue un acto inconsciente en Claudio Gay. Además de todo lo expuesto, ya en 1831 advertía sobre el valor del reconocimiento geográfico para tal efecto cuando explicó que "deseando hacer un trabajo absolutamente nacional, he considerado dedicar a los beneméritos de la patria todos los volcanes, islas, etc., que tenga ocasión de visitar en mis excursiones"13.

La preparación de los planos de las bahías y los puertos de Chile fue otro de los aciertos del hombre de ciencia. Representa los más importantes de entonces, como Valparaíso y Constitución, tanto por su valor estratégico, como por el tráfico que se realizaba a través de ellos. También incluye un plano de Santiago con el detalle de su traza, reconociendo así el papel preeminente que, desde su fundación, había tenido la ciudad para la sociedad chilena. Por último, la inclusión en su obra del plano de la batalla de Maipú, que en 1818 había sellado la independencia nacional, ejemplifica que tras la elección de las estampas existió una meditada decisión destinada a destacar los hitos constitutivos de la nación. Ejemplo a su vez del imaginario sobre el país presente en los chilenos de aquel periodo fundacional.

Hasta la aparición del "Plano topográfico y geológico de la República de Chile" y del "Mapa de la República de Chile desde el río Loa hasta el cabo de Hornos" de Amado Pissis en 1873 y 1888 respectivamente, levantados luego de una completa medición geodésica del territorio, la cartografía de Chile de Claudio Gay fue la usada por el Estado y sus agentes, como por los particulares, a pesar de las omisiones y errores que contenía.

Más trascendente que la ubicación exacta de las coordenadas o la confiabilidad de los accidentes del terreno representados, en definitiva, más que la llamada "verdad topográfica", importa la imagen de Chile que los mapas contribuyeron a fijar en la conciencia nacional. La cual, por

Véase "Viaje científico. Segundo informe sobre sus exploraciones en la provincia de Colchagua", en Stuardo Ortiz, II, p. 101. 
lo demás, no sólo guio la acción del Estado entonces, además, ha permanecido vigente como elemento esencial de la nacionalidad. Evidencia determinante a la hora de evaluar el papel de Gay como primer geógrafo de la república, pero sobre todo como científico capaz de proyectar socialmente el conocimiento resultado de su quehacer.

De este modo, la cartografía del naturalista no sólo se encuentra ligada indisolublemente al surgimiento del Estado-nación chileno, en tanto lo identifica, determina sus fronteras y caracteriza su topografía esencial; además, fue fruto de una iniciativa pública dirigida, precisamente, a dotar al Estado de los instrumentos necesarios para consolidarse, ejercer sus atribuciones soberanas y propender a la formación de la nación.

Los mapas del "Atlas de la Historia física y política de Chile", junto con representar la realidad, se anticipan a ella, transformándose en modelo de lo que debía contener el territorio del Estado republicano. A través de ellos se consolidan dominios, pero también se refuerzan pretensiones y se imaginan espacios nacionales por el sólo hecho de incluirlos en la cartografía chilena.

Siguiendo a Benedict Anderson, el "Mapa de Chile" de Claudio Gay se convirtió en verdadero logotipo del Estado-nación (Anderson, 2000). Al ser reconocido y transformarse en distintivo propio de Chile, penetró profundamente en la mentalidad colectiva, y no sólo a nivel nacional, pues evolucionó en emblema de la nación, en fuente y guía de su acción hacia el futuro; pero también en hito demarcador del territorio y de la acción de la sociedad que lo habitaba.

Claudio Gay da origen a la geografía chilena, en el sentido de definir el espacio nacional y diferenciarlo de otros por sus fronteras, sustrayéndolo así de la visión geográfica continental, regional, amplia que, al modo de Humboldt, había caracterizado el estudio de muchos naturalistas hasta comienzos del siglo XIX. Sin considerar que las unidades geográficas y las unidades espaciales se traslapan y tienen áreas de contacto muy fluidas, Gay, como muchos otros en su época, configura nítidamente un país, respondiendo así a las exigencias de la "geografía nacional", cuyo objetivo, precisamente, es la identificación del territorio de la nación.

Pero con su mapa y su obra el naturalista geógrafo marcó también el espacio donde se desenvolvería la "historia de Chile". Al fijar los contornos del país, delimitó no sólo la frontera material del Estado republicano, también el ámbito geográfico que debía tomar en cuenta la historia nacional.

De este modo, la historia de Chile, como la de muchos otros estados nación en América, es fruto de su materialización como espacio, como territorio, como unidad geográfica identificable y, por tanto, necesitada de un pasado que legitimara y dotara de contenido histórico a la naturaleza cartografiada que le sirve de guía.

La tarea de investigar el desenvolvimiento histórico de la comunidad nombrada Chile también recayó en el científico francés, por ser el único capaz de afrontarla al momento de hacerse indispensable, ahora como instrumento para afianzar una política y, también, la nacionalidad. Así, la historia resultó el complemento esencial de la realidad geográfica y social identificada por el científico. El fundamento de una comunidad en formación que se proyectaba hacia el futuro. 


\section{Referencias bibliográficas}

ANDERSON, B. Comunidades imaginadas. Reflexiones sobre el origen y la difusión del nacionalismo. Buenos Aires: Fondo de Cultura Económica, 2000.

APPELBAUM, N.P. Dibujar la nación. La comisión corográfica en la Colombia del siglo XIX. Bogotá: Universidad de los Andes, Fondo de Cultura Económica, 2017.

ARCE AGUIRRE, R.D. El naturalista francés Alcide d'Orbigny en la visión de los bolivianos. La Paz: Instituto Francés de Estudios Andinos, 2002.

BARROS ARANA, D. Don Claudio Gay; su vida y sus obras. En: Obras completas de Diego Barros Arana, tomo XI. Santiago de Chile: Imprenta Cervantes, 1911.

FELIÚ CRUZ, G. y STUARDO ORTIZ, C. Correspondencia de Claudio Gay. Santiago de Chile: Ediciones de la Biblioteca Nacional, 1962.

GAY, C. Historia física y política de Chile. Santiago de Chile: Biblioteca Nacional, Pontificia Universidad Católica de Chile y Cámara Chilena de la Construcción, 2007-2010.

PÉREZ RANCEL, J. Agustín Codazzi (1793-1859). Caracas: C.A. Editora El Nacional, 2006.

SAGREDO BAEZA, R. De la historia natural a la historia nacional. La Historia física y política de Claudio Gay y la nación chilena. En: GAY, C. Historia física y política de Chile. Santiago de Chile: Biblioteca Nacional, Pontificia Universidad Católica de Chile y Cámara Chilena de la Construcción, 2007-2010, Historia, I, p. IX-LVIII.

SAGREDO BAEZA, R. De la naturaleza a la representación. Ciencia en los Andes meridionales. Historia Mexicana, Vol. LXVII, No 2, 2017, p. 759-818.

SAGREDO BAEZA, R. El Atlas de Gay y la obsesión por representar Chile. En: Atlas de la Historia Física y Política de Chile de Claudio Gay. Santiago de Chile: LOM Ediciones y Centro de Investigaciones Diego Barros Arana de la DIBAM, 2004, p. 9-55.

SAGREDO BAEZA, R. y GONZÁLEZ LEIVA, J.I. La Expedición Malaspina en la frontera austral del imperio español. Santiago de Chile: Editorial Universitaria y Centro de Investigaciones Diego Barros Arana, 2004.

SÁNCHEZ, E. Gobierno y geografía. Agustín Codazzi y la Comisión Corográfica de la Nueva Granada. Bogotá: Banco de la República y El Áncora Editores, 1998.

SCHLÖGEL, K. En el espacio leemos el tiempo. Sobre historia de la civilización y geopolítica. Madrid: Ediciones Siruela, 2007.

STUARDO ORTIZ, C. Vida de Claudio Gay. Escritos y documentos. Santiago de Chile: Fondo Histórico y Bibliográfico José Toribio Medina y Editorial Nascimento, 1973. 
Sesiones de los cuerpos legislativos de la república de Chile. 1811 a 1845 (Valentín Letelier, recopilador) tomos VII y VIII. Santiago de Chile: Imprenta Cervantes, 1889.

VILLACORTA O., L.F. Antonio Raimondi, semblanza de un naturalista enciclopédico. En: Informes y polémicas sobre el guano y el salitre (Perú: 1854-1877) de Raimondi. Lima: Fondo Editorial Universidad de San Marcos y Corporación Financiera de Desarrollo, 2003.

VILLACORTA O., L.F. y RAIMONDI, A. La naturaleza y la nación. En: Flora perpetua: arte y ciencia botánica en Antonio Raimondi. Lima: Asociación Educacional Antonio Raimondi, 2010, T. III, p. 64-101. 
